\title{
SOCIO-ECONOMIC CHALLENGES AT CAREGIVING (SPECIAL REFERENCE TO ALZHEIMER'S DISEASE)
}

\author{
C.M. Munasingharachchi ${ }^{1 *}$, V.Jeyaruban ${ }^{1 * *}$ and W.K.J.N. Priyantha ${ }^{1}$ \\ ${ }^{I}$ National Institute of Social Development, Sri Lanka
}

\begin{abstract}
Mental health is not a topic that is usually reconnoitered with an open mind, in Sri Lanka. An astonishingly large of number of people chooses to attribute mental health illnesses to supernatural phenomena. Some people conceal the existence of mental health conditions altogether, because of the humiliation and disgrace associated with these conditions. A dementia condition $50 \%$ - $60 \%$ is due to the outlook for Alzheimer's disease. The main objective was to identify the challenges confronted by caregivers of dementia patients in the informal care setting. 46 family members from the outdoor patient unit were selected from the Mental Health Unit of Karapitiya Hospital through purposive sampling. The research data were collected by Interviews, Case studies, Observations and Focus Group Discussion. The results showed that during the period of Alzheimer's disease, caregivers experience a range of situations, including: a need to learn about the disease; dealing with guilt; and handling situations of pain, addiction and physical and psychological suffering. In conclusion the study described the challenges of the daily lives of these families, explaining the importance of and highlighting the need to adopt tools and strategies that provide physical, emotional, psychological and financial support to family caregivers of patients with Alzheimer's disease. Social Work intervention in Micro, Mezzo and Macro levels for caregivers are also included in this study. Since the economical challenge is found to be the most defied area in informal care setting, it is necessary for the persons with mental disorders to be entitled with a wellstructured state financial assistant equivalent to persons with physical disabilities under the light of National policy on PWDs.
\end{abstract}

Keywords: stigma, persons with mentally challenged, caregivers, informal care setting

\section{Introduction}

Mental illness is an important public health problem, both in its own right and because of its alliance to other chronic diseases with their concomitant morbidity and mortality. The world health organization (WHO) estimates that one of four families worldwide has at least one member suffering from a mental disorder and those mental disorders will constitute the largest global burden of disease by the year 2020. The onset and chronic presence of mental illness in the family can be a stressful event or a crisis for the family members.

Dementia is a progressive, degenerative brain syndrome that affects memory, thinking, behavior and emotion. Dementia knows no social, economic, ethnic or geographical boundaries and affects people throughout the world. As dementia progresses, individuals affected need care with all aspects of daily life, worldwide families mostly provide this care? Alzheimer's disease is the most common cause of dementia and accounts for 50-60\% of all cases and is caused by abnormal brain tissue changes. International studies make it clear that dementia occurs in every country of the world. Dementia affects 1 in 20 people over the age of 65 and 1 in 5 over the age of 80 . As of 2015, worldwide, there are an estimated 46.8 million people with dementia. By 2050 the number will rise to 131.5 million. For at least the last 15 years, the majority of people with dementia worldwide have been living in developing regions of the world. They already account for over $58 \%$ of all cases; by 2050 this proportion will have risen to $68 \%$.

Recent years have seen increasing awareness about the role of caregivers in the long-term management of psychiatric patients, and there is growing a body of literature on the caregiver burden, poor caregiver outcomes,

Corresponding Author Emails: *maduchathu@yahoo.com

**Jeyruban10@gmail.com 
lack of caregiver support, and equivocal success, with interventions aimed at relieving the care-giving burden. It has also become clear that the emphasis in psychiatric rehabilitation needs to shift from a patient-focused approach to a combined patient- and caregiver-focused approach.

Families generally have little prior knowledge of mental illness and find that not only do they have to deal with the upheaval that often accompanies the disease but also many of the natural supports that they have come to rely on in difficult times are no longer available to them in their time of need. This is often due to a lack of awareness and often stigma about mental illness among typical sources of support such as extended family members, friends, and co-workers.

Care givers play a vital role in supporting family members who are sick, feeble, or disabled. There is no doubt that the families of those with mental disorders are affected by the condition of their loved ones. Families not only provide practical help and personal care but also offer emotional support to their relative with a mental disorder. Therefore, the affected person is dependent on the care giver, and their well-being is directly related to the nature and quality of the care provided by the care giver.

These demands can create significant levels of stress for care givers and can affect their overall quality of life, including work, socializing, and relationships. Research into the impact of caregiving shows that one-third to one-half of care givers suffer significant psychological distress and experience higher rates of mental ill health than the general population. Being a care giver can raise difficult personal issues about duty, responsibility, adequacy, and guilt. Caring for a relative with a mental health problem is not a static process since care recipients alter as their condition changes. The role of the care giver can be more demanding and difficult if the care recipient's mental disorder is associated with behavioral problems or physical disability. Providing care for a patient with mental illness can be debilitating, stressful, and burdensome for the caregiver. In contrast, providing care to chronically ill or incapacitated family members may have a positive impact on family caregivers such as increased self-respect or self-satisfaction from fulfilling a responsibility.

Care givers provide significant services at home to their relatives who need their help; however, lack of sufficient information and resources has always been an obstacle. As a result, care givers are ill-prepared to play their roles as efficiently as possible. Sri Lankan families are characterized by their intimate interpersonal relationships and many interactions among family members. Consequently, illness in one family member results in a substantial burden on the whole family.

Caring for elderly people with Alzheimer's is an arduous task. The caregiver often does not devote sufficient attention to their own needs, due to the daily demands of care, including comfort, safety, help in activities of daily living (ADL) and tasks related to domestic chores.

The primary caregiver is directly responsible for all these actions. In contrast, while secondary caregivers may perform the same tasks as the primary caregiver, they do not have the same level of responsibility and decisionmaking authority. Tertiary caregivers are supportive, replacing the primary caregiver for short periods, and usually perform specialized tasks such as shopping, assisting in patient transportation, collecting pensions, and paying bills. While all play an important role in care, it is clear that the responsibility for providing care and attention rest with the primary caregiver.

In this context, the aim of the present study was to analyze the main difficulties of family caregivers of sufferers of Alzheimer's disease (AD) in Galle District, Southern Province in Sri Lanka.

\section{Methodology}

A qualitative, descriptive study was performed by interviewing 46 caregivers of patients with AD living in Galle District, Sri Lanka. All were family care giver of Alzheimer Patients who were selected through purposive 
sampling method at the outdoor patient care unit at Karapitiya Teaching Hospital in Galle District. The inclusion criteria adopted were: having been a family caregiver of elderly persons with AD for one year or more, while living in the same household. Apparently, Key Informant Interviews (KII) was conducted with the psychiatric social worker of the area, consultant and two elder rights promotion officers from Galle District in Sri Lanka. In order to develop an insight to the community perception on the informal caregiving for the persons with mental disorders, Focused Group Discussion (FGD) was conducted parallel. Moreover, selected three case studies were employed in enriching the thematic information of the study.

From the thematic analysis adopted, the data was organized into seven analysis categories to enable the grouping of the answers obtained and discussion about the discourses. In each of the four categories different aspects of care were perceived, which were organized into subcategories. The results will be presented through the analysis of themes and its subcategories.

\section{Results and Discussion}

The caregivers participating in this study were aged between 24 and 72 years, and the primary family caregivers were predominantly women. 67.39 percent were female caregivers while the rest is male care givers. The caregivers' relationship to the patient can be categorized as spouse (30.44\%), daughter (19.56\%), son (10.86\%), brother $(03.51 \%)$, sister $(06.51 \%)$, daughter in law $(18.22 \%)$, and granddaughter $(10.86 \%)$. Additionally, their economic status varies from lower class to middle class. It should be emphasized that socioeconomic variables increase the physical, emotional, social and financial difficulties of caregivers.

Another factor exhibited was the religion professed by the attending caregivers. All had a basis in Buddhism $(82.60 \%)$ and Christianity $(17.39 \%)$. Knowing the religion of each person is important because, in general, it is through religious practices that caregivers express their spirituality.

The fact that caregivers are mostly female can be attributed to the historical division of labor between men and women and the gender differences that attribute the care of other family members to women. In this sense, women themselves may consider care as a mission and the focus of their existence, related to giving birth, which connects them to all aspects of life and care. In addition, female dominance occurs because the female population of the country is greater. This affirmation also follows the cultural norms that expect men to provide sustenance and authority and women to care for the children, the house and the elderly.

In the opinion of Boss, care is, More than an action: it is an attitude. Therefore, it covers more than the moment of attention, of zeal and care. It represents an occupation and attitude of concern, responsibility and involvement with another.

Care has an existential character and arises when the caregiver understands his own subjectivity and that of the individual receiving the care, with this relationship expressing itself in such a way that the individuality, autonomy and freedom of the other are respected.

\section{Reasons for Family Caring}

Family caregivers may be motivated to provide care for several reasons: a sense of love or reciprocity, spiritual fulfillment, a sense of duty, guilt, social pressures, or in rare instances, greed. Caregivers who are motivated by a sense of duty, guilt, or social and cultural norms are more likely to resent their role and suffer greater psychological distress than caregivers with more positive motivations. Caregivers who identify more beneficial components of their role experience less burden, better health and relationships, and greater social support 


\section{Theme 01: Characteristics of the Caregiver}

Older caregivers may have less access to information about dementia care in their daily lives and therefore show greater improvements in knowledge. Women show more improvements in depression and knowledge but less improvement in subjective well-being than men. Caregivers with less education may respond more favorably to a multicomponent intervention while Sri Lankans may respond less to interventions with regard to depression and burden outcomes even as they derive benefits in quality of life. Finally, spouses benefit more from interventions with regard to decreasing the number and bother of patient's problem behaviors as well as delays in nursing home placement. Thus, interventions should be individualized to caregivers' cultural and educational background, current knowledge and skill, mental health status, physical health status, and personality.

\section{Theme 02: Difficulties in the care of Family Members with Alzheimer's disease}

Regarding the difficulties encountered in the care of individuals with $\mathrm{AD}$, the data analysis revealed three main aspects: hygiene and comfort, a constant need for attention and a lack of knowledge about the disease.

\section{Sub Theme 2.1. Hygiene and Comfort}

The limitations of patients with $\mathrm{AD}$ involve an inability to perform activities of daily living (ADL) and require the family caregiver to be constantly present in tasks of hygiene and comfort, aggravating feelings in the caregiver that fluctuate between anger, due to the stubbornness of the patient, and pity, due to having a family member with a progressive and irreversible disease. In this subcategory, bathing, combined or not with the resistance of the patient, stood out, as can be seen in the following statement:

"It's my mother's resistance to bathing, she resists and fights a lot, she does not want to bathe at all" (son, 41 yrs.)

"It's giving her a bath, when she's calm, it's fine, if she gets upset she resists, so I have to let her do some little things" (Daughter in law, 37yrs).

"The greatest difficulties I have with taking care of my brother with Alzheimer's are brushing his teeth because he forgets, and bathing, because I have to lower myself and I have spinal problems and a lot of pain in my body" (Sister, 24 yrs.).

There are other difficulties arising from secondary complications of the pathological processes of the AD patient which also make care difficult:

"Well, I don't think there is a specific task, it is the group of small tasks that go on all day, personal hygiene and food, because she recently underwent bowel surgery and had an ileostomy. This further aggravated her health" (Spouse, 62 yrs.).

The daily tasks of the caregiver are influenced by the limitations imposed by AD, by the additional pathological processes of the AD sufferer, and especially by the health condition of the caregiver themselves.

Sub Theme 2.2. Constant need for attention

This subcategory identifies the constant attention required by elderly relatives with $\mathrm{AD}$ as one of the challenges faced by caregivers, as the discourses confirm:

"Manage what he does. Accept what he does. Follow him closely, stay close to him. You have to be constantly supervising what he does, because he no longer sees the extent of the danger of what he is doing" (Daughter, 49 yrs.). 
"My greatest difficulty is paying constant attention because she is very forgetful and often puts her at risk when she is near cleaning products. A few days ago we found her wanting to drink detergent. So I believe that my main difficulty has to always pay attention so as not to let her get into danger" (daughter in law, 52 yrs.).

The intensive care and attention are necessary in ADL mainly due to the impairments caused by the disease and the loss of autonomy and independence that result from it. The dependency that makes a caregiver necessary is revealed by an inability to care for oneself satisfactorily without the help of others, as well as in the loss of decision-making capacity.

According to the International Classification of Functioning, Disability and Health (ICF), activity limitations are difficulties that an individual may have in performing activities, and the capacity and ability of an individual to perform a task or action. Dependence is a condition of elderly persons, the basic characteristic of which is the immorality resulting from chronic diseases or other pathologies, which threatens their physical, social and economic integrity, diminishing or impeding the individual's ability to meet his or her needs.

Another aspect highlighted in the discourse presented was the shocks that the caregiver suffers due to the situations of risk in which the patient is involved, which generates anguish, fears and ambivalent feelings towards the individual receiving care. In the dependency phase, the changes that take place in the new life dynamic of the caregiver completely change his or her daily life. These include preparing food, administering medications, establishing a routine for exercises and activities of comfort, including personal hygiene, hair combing, teeth brushing, fingernail cutting, dressing, undressing, moving from one place to another, climbing stairs, sitting, getting up, and lying down, among many other activities.

Sub Theme 2.3. Lack of knowledge about disease

This subcategory revealed a fundamental difficulty for family caregivers regarding the caring process. It denotes to knowledge of the disease and its evolution.

The interviews frequently expressed the view that their challenges would be lessened if they had known in advance about the possible situations that could occur and how to act when faced with each one of them. This fact is evidenced in the statements of three participants.

"The main difficulty is to understand how this works in his mind. To understand how things go through his mind and the best way to live, in order not to cause him any more pain than he has already suffered. We don't understand many things happened to him" (son, 43 yrs.).

"I don't know when I should take her to the doctor. If she doesn't urinate, I will give her medicine to make it. It's the same thing with defecation. She refuses to eat and we worry about whether it's time to take her to the doctor or not" (Spouse 64 yrs.).

The exercise of caring for an elderly patient at home is a constant learning process, based on the physical and biological needs of the individual and his or her level of dependence. In most cases, it is difficult, due to the inexperience of the caregiver, to meet the demands that arise during the process of caring and which must be learnt to meet the challenges of everyday life. Activities that seem simple to those who have already developed become demanding for those who have never had to confront them.

As the data indicates, ignorance of $\mathrm{AD}$ is a crucial point for caregivers, especially as care in Sri Lanka is curative and centered on the individual, with teams working in a fragmented manner, which devalues the family situation and the sociocultural context 
In this sense, it is imperative that caregivers are constantly monitored and receive guidance on the evolution of the disease, as well as on the care needed at each stage. This is necessary for efficient care, which results in safety and support, to be provided, and can foster an information exchange network capable of minimizing the stress of the family caregiver.

Better informed and more experienced caregivers are less anxious and more secure in their provision of care, which is reflected in a greater capacity and availability to take care of the patient. Health and social institutions should make all their information available to the caregiver. Nurses can jointly propose a care plan to delay the degenerative effects of $\mathrm{AD}$ and allow the elderly person to live with the signs and symptoms in the best possible way. Figure 01: Model of caregiver burden

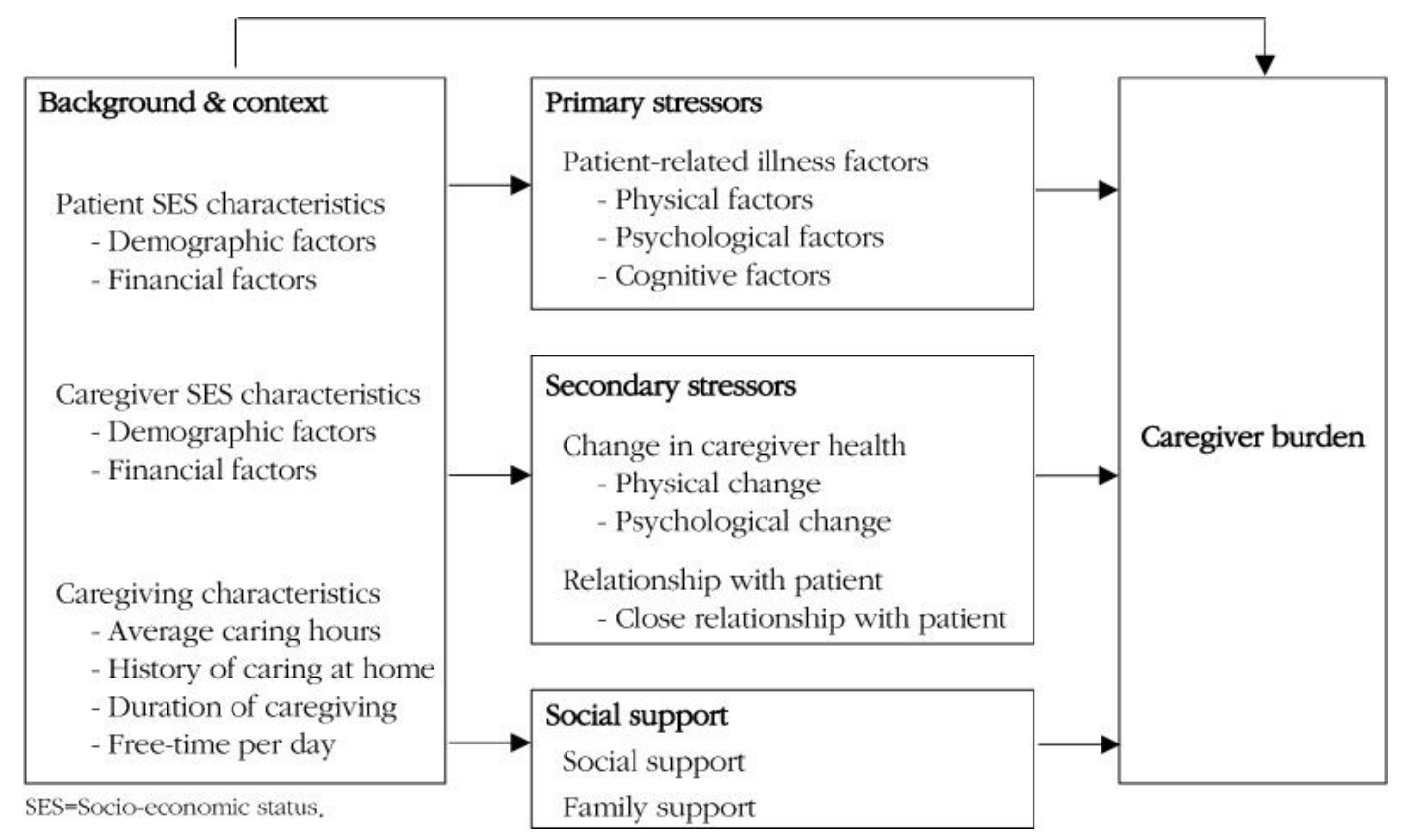

This model was designed to assess the informal caregiving processes affecting caregiver health. Similar to other models described above, Aneshensel et al. and Pearlin et al. applied the stress process model to the caregiving of older adults with dementia who at one point were independent but where the relationship had now changed to one where the caregiver was responsible for meeting all the needs of the older adult with dementia.

As mentioned earlier, the caregiving experience and associated stress process reflects a process that changes over time. Pearlin and colleagues define stressors as the "problematic conditions and difficult circumstances experienced by caregivers" that strain or supersede the individual's capacity to adapt. These are conceptualized as primary and secondary in nature. The primary stressors are linked directly to the individual and the disability, while the secondary stressors arise from the demands of the caregiving role itself. The potential proliferation effects of the stress involved in the caregiving role highlight the existence of a complex stress process. This conceptualization allows for numerous instances for the moderators to impact the situation. The moderators include social supports and concepts of mastery or self-efficacy, which determine how people are impacted differently by the same stressors, and may help to sustain the caregiver and lessen the effect of the stressors

\section{Theme 03: Characteristics of the Intervention}

Individualized interventions can be more easily adapted to the specific needs of the caregivers and may, therefore, be more effective for modifying burden or distress for caregivers in general. However, interventions in groups are more effective in increasing social support and those that avoid dilution of the participant's active involvement are likely to be as effective as individual approaches. Longer interventions generally are more 
effective at reducing distress and delaying institutionalization. Even single-component interventions, if they last longer or involve more frequent interactions, tend to have stronger effects than less intense interventions that have multiple components.

\section{Sub Theme 03.1: Coping Method}

The caregivers were using multiple coping strategies, which included positive emotions like compassion, hope for a better future, and developing faith in God, participating in religious practices and helping others with a similar problem and taking regular guidance from the experts.

Caregivers expressed a wide range of emotions in their caregiving role ranging from concern, confusion, frustration, fear, sadness, grief, anger, resentment, and guilt to hope, caring, compassion, sympathy and love. The emotions varied from time to time, while caring for their relative. Both positive as well as negative emotions were reflected at different times. A spouse said, "I have become more compassionate and try more and more to learn about the disease and its management." Positive and compassionate approach and supportive handing of the patient was a common method of caregiving.

Having faith in God was an important coping strategy voiced by many caregivers. Most caregivers felt that one should do one's duty of taking care of their relative with illness. One should provide him/her with the best treatment and leave everything else for God. Religion was often a source of support. Most caregivers believed in God and thought that He would help them out of this situation. Some of the statements were, "I do weekly fasting so that he gets well soon" "I pray every day and it helps me in difficult times." Religious methods of coping have been reported by earlier workers.

\section{Conclusion}

This study has indicated a significant gap in the life and health of the caregiver, specifically the need for health professionals to provide understandable explanations, exchange experiences, and promote openness and dialogue about the disease so that care can be performed safely at home.

Thus, getting to know families that welcome subjects with $\mathrm{AD}$, who they are, what they do, where they work and other characteristics can help in the organization of their routines, reducing situations of conflict and supporting the fragilities imposed by the disease.

During the interviews, it was perceived that each caregiver of AD patients presented individual distinctiveness in their discourses about care, as the singularity of the disease in each patient, the length of time each caregiver has cared for their family member and even the time of discovery of the diagnosis are limiting factors for a generalization about the challenges faced in everyday life. Thus, it is important to consider the specific profiles of patients with $\mathrm{AD}$ and the contexts involved in the exercise of care for the elderly.

This study provided information about part of the daily life of those who act as caregivers of people with Alzheimer's Disease, as well as the difficulties, emotions, limitations, and stress they face, but also the dedication with which they take care of their family member.

Greater life expectancy brings with it greater risks of developing dementias such as Alzheimer's disease, patients of which require home care, resulting in changes in the daily lives of many families. The present study found that, when caring for a family member with Alzheimer's disease, the caregiver experiences different feelings and requires attention and care from health professionals and public policies. While secondary and tertiary caregivers deserve our attention, it is the primary caregiver who carries the greatest burden and needs the most support. Caring for a family member with Alzheimer's disease requires the caregiver to learn to live with the suffering of another, often having to disguise their pain and needs. They are required to do almost everything, whilst knowing almost nothing. In addition, cohabitation with a family member with Alzheimer's disease 
requires that the caregiver abandons many aspects of his or her personal life for the benefit of another, which increases the risk of personal and family illness.

It is the responsibility of health professionals to develop practices that seek and enable dialogues, respecting the knowledge, beliefs and environments of caregivers while providing training to caregivers with the purpose of guaranteeing quality care for Alzheimer's disease patients and support for the caregiver. In this sense, by providing assistance to caregivers, professionals who are capable of guiding and intervening in the face of family conflicts and challenges, contribute to supporting those experiencing moments of frailty.

The current reality in Sri Lanka, especially in relation to increasing population aging, requires urgent government measures of social and health care that encourages the family as a place of care. What can be verified, however, is that national policy on mental health still needed to be revised for a systematic home-based and community based caring system for its service users.

There is, however, an urgent need for attention to be paid to these family caregivers, especially from public authorities, through the provision of trained professionals to deal with families, and not just patients. This issue is crucial for the family caregiver, since it requires health professionals to provide clear information, as well as objective and comprehensible skills related to the disease, its symptoms and its progression. In this way, the caregiver will be prepared to provide safer and less stressful home care.

\section{References}

Albert MS., DeKosky ST., Dickson D., Dubois B., Feldman HH., Fox NC., Gamst A., Holtzman DM., Jagust WJ., Petersen RC., Snyder PJ., Carrillo MC., Thies B., Phelps CH. (2011). The diagnosis of mild cognitive impairment due to Alzheimer's disease: Recommendations from the National Institute on Aging-Alzheimer's Association workgroups on diagnostic guidelines for Alzheimer's disease. Alzheimer's and Dementia. 7 (3): 270-279.

Alzheimer's Association. (2008). More Men Take the Lead Role in Caring for Elderly Parents, Retrieved from: http://www.alz.org/news_and_events_in_the_news. Asp.

Aneshensel C.,S, Pearlin L.,I, Mullan J,T, Zarit S, H, Whitlatch C., J. (1995). Profiles in caregiving; The unexpected career. San Diego, Academic Press, Inc.

Boss P. (1992). Primacy of perception in family stress theory and measurement. Journal of Family Psychology

6:113-119.

Elbogen EB., Van Dorn RA., Swartz SMS. (2006). Treatment Engagement and Violence Risk in Mental Disorders, British Journal of Psychiatry (Oct. 2006): Vol. 189. pp. 354-60.

Marder K. (2012). Dementia and memory loss. In JCM Brust, ed. Current Diagnosis and Treatment Neurology, 2nd ed., pp. 78-101. New York: NcGraw-Hill.

McKhann GM., Knopman DS., Chertkow H., Hyman BT., Jack CR Jr., Kawas CH., Klunk WE., Koroshetz WJ., Manly JJ., Mayeux R., Mohs RC., Morris JC., Rossor MN., Scheltens P., Carrillo MC., Thies B., Weintraub S., Phelps CH. (2011). The diagnosis of dementia due to Alzheimer's disease: Recommendations from the National Institute on Aging-Alzheimer's Association workgroups on diagnostic guidelines for Alzheimer's disease. Alzheimer's and Dementia, 7 (3): 263-269.

Nehra R, Chakrabarti S., Kulhara P., Sharma R. (2005). Caregiver-coping in bipolar disorder and schizophrenia - A re-examination. Soc. Psychiatry Epidermal.

Pearlin LI, Mullan JT, Semple SJ, Skaff MM. (1995). Caregiving and the stress process: an overview of concepts and their measures. Gerontologist. 1990;30:583-594.

Sperling RA., Aisen PS., Beckett LA., Bennett DA., Craft S., Fagan AM., Iwatsubo T., Jack CR Jr., Kaye J., Montine TJ., Park DC., Reiman EM., Rowe CC., Siemers E., Stern Y., Yaffe K., Carrillo MC., Thies B., Morrison-Bogorad M., Wagster MV., Phelps CH. (2011). Toward defining the preclinical stages of Alzheimer's disease: Recommendations from the National Institute on Aging-Alzheimer's Association workgroups on diagnostic guidelines for Alzheimer's disease. Alzheimer's and Dementia. 7 (3): 280-292. 
C.M. Munasingharachchi et al / Socio-Economic Challenges At Caregiving (Special Reference ....

Wilson, R.S., Segawa, E., Boyle, P.A., Anagnos, S.E., Hizel, L.P., Bennett, D., A. (2012). The natural history of cognitive decline in Alzheimer's disease. Psychol Aging. 2012;27:1008-1017.

World Health Organization. (2002). strengthening mental health. Resolution of the Executive Board of the WHO. Geneva. EB109.R8 